\title{
Gender, BMI, and Personality as Predictors of Self-Assessed Attractiveness and Intelligence
}

\author{
Adrian Furnham \\ Research Department of Clinical, Educational and Health Psychology, University College London, London, UK \\ Email: a.furnham@ucl.ac.uk
}

How to cite this paper: Furnham, A. (2017). Gender, BMI, and Personality as Predictors of Self-Assessed Attractiveness and Intelligence. Psychology, 8, 2333-2345. https://doi.org/10.4236/psych.2017.814147

Received: November 2, 2017

Accepted: December 4, 2017

Published: December 7, 2017

Copyright (C) 2017 by author and Scientific Research Publishing Inc. This work is licensed under the Creative Commons Attribution International License (CC BY 4.0).

http://creativecommons.org/licenses/by/4.0/

\begin{abstract}
Over 2000 students completed three short questionnaires in which they rated their general and multiple intelligence, their attractiveness and personality using a shortened measure of the Big Five. They also provided information about their weight, height, religious and political beliefs. A series of regression was performed with self-rated intelligence and attractiveness as the criterion variable. Females scored higher on Neuroticism and Agreeableness and lower on Openness, Self-estimated IQ and attractiveness. Regressions for self-estimated IQ and Attractiveness showed a similar pattern: Conscientious, Disagreeable, Extraverted, Lower BMI males gave higher scores. Regressions for the different "multiple intelligences" showed that four (Logical, Spatial, Interpersonal, Spiritual) of the nine predictor variables accounted for 10 or more percent of the variance. For the "Academic intelligences" results showed that Conscientious, Open, Extraverted males gave higher scores. Implications and limitations are considered.
\end{abstract}

\section{Keywords}

Self Assessed Intelligence, Attractiveness, Big Five Personality Variables, Gender, BMI

\section{Introduction}

This study examines the correlates of self-assessed intelligence (general and multiple) and self-rated attractiveness (physical and facial). Specifically it examines gender, body shape (MBI), personality and ideological correlates of self-assessed overall, as well as "multiple" intelligences and overall and facial attractiveness. Whilst the former criterion variable has been extensively studied, the latter has not, and this study seeks to investigate whether correlates of these two different ratings are similar and tapping into a general self-esteem concept. 


\section{Self-Assessed Intelligence}

\subsection{General Intelligence}

Self-estimated intelligence (SEI) is a topic of considerable current interest (Freund \& Kasten, 2012; Kaufman, 2012) for various reasons: first to help people with poor insight into their performance, notably people whose self-estimates are very different from their objective scores (Schlosser, Dunning, Johnson, \& Kruger, 2013). Second, to look at the individual differences and processes (like social desirability, hubris, ability test experience) that lead to good and poor insight about abilities (Paulhus, Lysy, \& Yik, 1998). Third, to assist in self- awareness as it relates to career choice (Ackerman \& Wolman, 2007).

The studies have been done in many countries from Austria (Stieger, Kastner, Voracek, von Stumm, Chamorro-Premuzic, \& Furnham, 2010) to Spain (Perez, Gonzales, \& Beltran, 2010) and Switzerland (Proyer, 2011). They have examined gender as well as cultural, differences in self-estimates of ability (Ivcevic \& Kaufman, 2013). One study compared sex differences in self-estimated intelligence across 12 countries (von Stumm, Chamorro-Premuzic, \& Furnham, 2009; von Stumm, 2013). Some of these studies have also investigated participants' beliefs about intelligence (such as whether there are sex differences) and experience of tests to examine whether these beliefs are related to self-estimates (Furnham \& Fukumoto, 2008). It should be noted that in all these studies, and in this paper, intelligence is entirely and only about self-estimated intelligence, not about actual, psychometrically tested intelligence. Where the two have been correlated the results show that overall people are poor at estimating their intelligence score with correlations typically between $r=.2$ and $r=.4$ (Furnham, 2001).

\subsection{Multiple Intelligence}

Over thirty studies that used the "multiple" self-estimated intelligence model (Furnham, 2000; Furnham \& Bunclark, 2006) have found that gender differences were strongest on the Mathematical/Logical and Spatial intelligences, followed by overall ("g") and verbal intelligences, with males significantly overestimating and females significantly underestimating their abilities. This consistent gender difference has been referred to as the Hubris-Humility Effect (HHE) (Storek \& Furnham, 2012ab).

A meta-analytical study investigating the magnitude of gender differences in Mathematical/Logical, Spatial, overall and Verbal self-assessed intelligences (Szymanowicz \& Furnham, 2011), found that the biggest weighted mean effect sizes were for Mathematical/Logical, $(\mathrm{d}=.44)$, followed by Spatial $(\mathrm{d}=.43)$, overall $(\mathrm{d}=.37)$ and Verbal $(\mathrm{d}=.07)$ intelligence, with males providing higher estimates in all but Verbal intelligence. Mathematical, Spatial and Verbal intelligences were the best predictors of self-estimated overall intelligence, as demonstrated through numerous multiple regression analyses (Furnham, 2001). This finding led Furnham (2000) to conclude that gender differences in SEI reflect laymen's view of intelligence, i.e. an amalgamation of Verbal, Mathematical and 
Spatial intelligences. Furnham (2000) proposed that people view intelligence as 'male-normative', since Mathematical/Logical and Spatial intelligences are areas where males are believed to excel (Storek \& Furnham, 2012ab).

There is also a literature on the personality correlates of both actual intelligence test scores and self-estimated intelligence. The results tend to show small, but significant, positive correlations with Openness (particularly facets that measure Intellectance) and negative correlations with Neuroticism. Some studies have shown Extraversion correlated with self-estimated intelligence (Gardner, 1999) whilst others note a consistent, small, but negative correlation between Conscientiousness and psychometric test scores of intelligence (Moutafi, Furnham, \& Paltiel, 2004).

\subsection{Self-Rated Attractiveness}

Researchers have not only investigated how people rate their own intelligence, they have also studied how people rate their own attractiveness. This is important as self-ratings have been linked to various issues like eating disorders and depression.

There are a few papers on the correlates and consequences of self-rated (physical) attractiveness (Bale \& Archer 2013; Swami, Furnham, Geogiades, \& Pang, 2007; Swami, Waters, \& Furnham, 2010). The results tend to be consistent: there are few sex differences in self-ratings overall but when very specific body parts are rated, there are small and replicable differences. Females tend to rate their facial attractiveness, as well as breasts/chests, higher than men. People rate the overall and specific attractiveness of their partners significantly higher than they rate themselves. Self-ratings of attractiveness are closely linked to overall self-esteem. Interestingly there is evidence of the "love is blind" thesis which suggested that people tend to rate the attractiveness of their partner much higher than their own attractiveness.

\section{The Present Study}

This study replicates (examining gender and personality variables) and advances (using religious and political beliefs) the literature in this field of self-rated intelligence and self-rated attractiveness which seem related components of a general self-esteem concept. First, sex and personality correlates of self-estimated intelligence are investigated. It is predicted that males more than females, Stable more than Neurotic, Extraverted more than Introverted, Open vs Closed and Conscientious vs Unreliable students will give higher self-estimates on overall, as well as the Gardner (1999) ten and Sternberg (1997) three multiple intelligence. However it also, and uniquely, investigates "ideological" correlates, namely religious and political belief correlates of self-rated intelligence. From other studies using these variables it is hypothesised that less religious and more right wing people will give higher intelligence scores (Furnham, 2001).

It is predicted that males more than females, thinner rather than fatter (as 
measured by BMI), Stable more than Neurotic, Extravert more than Introvert and Disagreeable rather than Agreeable students would give higher scores. It is also hypothesised that when using gender, BMI, personality and ideology as predictors, results for both self-rated overall intelligence and physical attractiveness will be similar, indicating a general self-esteem measure. Also, after gender, the best predictor of self-rated intelligence is self-rated attractiveness and vice versa.

Next, there is a related academic literature on the relationship between (actual- as opposed to self-rated) intelligence and personality. Some of this literature is based on observational data and referred to as the "halo effect" (Moore, Filippou, \& Perrett, 2011), others on empirical data called the "good gene effect" (Kanazawa, 2011) and some on self-rated data called the "self-illusion effect" (Gabriel, Critelli, \& Ee, 1994). Gabriel et al. (1994) found that trait narcissism predicted both the attractiveness and intelligence illusion and that positive illusions based on self-ratings for intelligence and attractiveness were correlated. All studies show a small positive, significant relationship between objective, other and self-rated measures of attractiveness and intelligence but tend to offer different explanations for the phenomenon. It is predicted in this study that self-rated intelligence and attractiveness will be significantly positively correlated, reflecting a general self-esteem measure.

Finally this study explored the difference score in self-rated intelligence and attractiveness to explore those who saw a big difference in the former over the latter. It was predicted that males, those with a higher BMI, Open and Conscientious people would have a higher difference score, as they rate intelligence over attractiveness in themselves whereas the opposite is true in females (Swami et al., 2010).

\section{Method}

In all 2282 students took part in this study. There were 808 males and $1467 \mathrm{fe}$ males. Their average age was 23.40 years $(S D=9.33)$. They had an average BMI of 22.16. Rated on a 7 point scale of religiousness $(1=$ Not at all, $7=$ Very $)$ the mean was $3.04(\mathrm{SD}=1.51)$. Rated on a 7 point political beliefs scale $(1=\mathrm{Ex}$ tremely Right Wing, 7 = Extremely Left Wing) the mean was $4.00(\mathrm{SD}=1.42)$. Most were unmarried.

\subsection{Questionnaire}

Self-rated intelligence and attractiveness questionnaire. Participants were provided a one-page questionnaire including a normal distribution curve for IQ scores with a mean of 100 and six standard deviations of 15 points used in all studies (Furnham et al., 2012). They made 14 ratings of intelligence including "Overall intelligence", Gardner's (1999) ten multiple intelligence and Sternberg's (1997) Emotional, Creative, and Practical intelligences for themselves. They rated their overall physical and facial attractiveness on the same scale. This measure has been used in over 30 studies (see Table 1 ) where participants have 
Table 1. Sex differences on all the major variables.

\begin{tabular}{|c|c|c|c|c|c|}
\hline & Male Mean & Male SD & Female Mean & Female SD & $\mathrm{F}$ \\
\hline Overall & 117.5 & 11.8 & 109.4 & 10.7 & $183.51^{* * *}$ \\
\hline Verbal & 115.0 & 14.6 & 108.8 & 13.3 & $78.82^{* * *}$ \\
\hline Logical & 113.9 & 16.9 & 103.5 & 14.0 & $187.94^{* * *}$ \\
\hline Spatial & 116.1 & 14.2 & 103.8 & 13.6 & $302.33^{* * *}$ \\
\hline Musical & 106.1 & 18.3 & 103.4 & 32.6 & 3.33 \\
\hline Kinaesthetic & 109.7 & 15.6 & 107.5 & 28.6 & 3.07 \\
\hline Inter-personal & 114.9 & 12.2 & 116.2 & 13.3 & 2.55 \\
\hline Intra-personal & 113.7 & 14.4 & 111.7 & 14.1 & $7.63^{\star *}$ \\
\hline Existential & 112.6 & 15.9 & 111.3 & 31.3 & 0.77 \\
\hline Spiritual & 106.4 & 17.4 & 104.4 & 15.6 & $5.83^{* *}$ \\
\hline Naturalistic & 107.7 & 16.6 & 103.3 & 15.5 & $28.71^{\star \star \star}$ \\
\hline Emotional & 112.5 & 14.7 & 111.8 & 14.9 & 0.89 \\
\hline Practical & 116.9 & 62.7 & 107.7 & 24.6 & $20.61^{\star * *}$ \\
\hline $\begin{array}{l}\text { Overall Physical } \\
\text { Attractiveness }\end{array}$ & 109.2 & 14.4 & 106.5 & 12.2 & $16.72^{\star * *}$ \\
\hline Facial Attractiveness & 108.8 & 15.1 & 107.2 & 13.1 & $4.82^{\star}$ \\
\hline BMI & 23.5 & 3.74 & 21.7 & 3.71 & $84.13^{\star * *}$ \\
\hline Religiousness & 2.88 & 3.09 & 2.98 & 1.61 & .44 \\
\hline Political Orientation & 4.26 & 4.84 & 4.13 & 1.52 & .59 \\
\hline
\end{tabular}

shown little or no difficulty in understanding the instructions and completing the task. A researcher, however, was on hand to answer any questions if they arose.

Personality measure. Participants were presented an abbreviated Big Five questionnaire based on the five-factor model of trait personality used in many studies. The questionnaire contained 15 items and each item was rated from 1 for "completely disagree" to 5 for "completely agree". The measure has been used in a dozen published studies (i.e. McManus \& Furnham, 2006) with alphas typically around .50 to .70 .

\subsection{Procedure}

Data was collected from students at a variety of universities over a 5 year period. They completed the questionnaire in class time and were given credits for their contribution. Where possible they were debriefed. Ethics committee approval was sought and received.

\section{Results}

Table 1 shows sex difference on all estimates as well as BMI and the two ideology scales. Just over half of the self-estimated intelligences showed a significant 
difference but with the exceptions of Spatial $(\mathrm{d}=.88)$, Overall $(\mathrm{d}=.72)$, Logical $(\mathrm{d}=.67)$ and Verbal $(\mathrm{d}=.44)$ the Cohen's $\mathrm{d}$ was small. Both attractiveness ratings showed a sex difference but they were small, the biggest being Overall Physical Attractiveness $(\mathrm{d}=.21)$. There was a significant sex difference on BMI $(\mathrm{d}=.48)$ though none on the two ideological factors.

The mean estimate for overall intelligence was $117.54(\mathrm{SD}=11.75)$ for males and $109.37(\mathrm{SD}=10.66)$ for females $(\mathrm{F}(1,1643)=183.51, \mathrm{p}<.001)$. The mean estimate for overall attractiveness was $109.23(\mathrm{SD}=14.43)$ for males and 106.52 $(\mathrm{SD}=12.23)$ for females $(\mathrm{F}(1,1846)=16.67, \mathrm{p}<.001)$. The difference score (intelligence - attractiveness) was $7.79(\mathrm{SD}=14.14)$ for males and $2.63(\mathrm{SD}=2.63)$ for females $(\mathrm{F}(1,1630)=49.85, \mathrm{p}<.001)$.

Table 2 shows the correlation between the major variables measured in this study. The results showed that females had a lower BMI, higher Neuroticism and Agreeableness scores, and lower self-estimated intelligence and attractiveness. This confirms most other studies in the area. Other correlations with an $r>10$ indicated that: BMI was negatively correlated with self-perceived physical attractiveness; that Stable Extraverts gave higher IQ and Attractiveness estimates; that Open people tended to be more left wing and gave higher self-rated IQ scores; that more religious people tended to be more right wing; and that those who gave high ratings for their own IQ did likewise for their intelligence.

Table 3 shows the results of three regressions with self-rated IQ, overall attractiveness and facial attractiveness as the criterion variables. Five sets of variables acted as predictor variables: sex, BMI, personality and ideology/values. A number of variables were significant predictors of overall intelligence. This showed Conscientious, Disagreeable, Stable, Extraverted Males tended to give higher scores. Political and religious beliefs, and were essentially unrelated to self-rated IQ.

Table 2. The means, SD's and correlates between the major variables.

\begin{tabular}{|c|c|c|c|c|c|c|c|c|c|c|c|c|}
\hline & Mean & S.D. & Gender & BMI & $\mathbf{N}$ & $\mathrm{E}$ & $\mathrm{O}$ & A & $\mathrm{C}$ & Relig & Pol & I.Q. \\
\hline Gender & $1.64^{\mathrm{a}}$ & .479 & & & & & & & & & & \\
\hline $\mathrm{BMI}$ & 22.17 & 3.77 & -.199 & & & & & & & & & \\
\hline Neuroticism $\mathbf{N}$ & 8.67 & 2.47 & .099 & .004 & & & & & & & & \\
\hline Extraversion E & 10.45 & 2.27 & .032 & -.055 & -.161 & & & & & & & \\
\hline Openness $\mathrm{O}$ & 10.60 & 2.17 & -.090 & .040 & .006 & .094 & & & & & & \\
\hline Agreeableness A & 11.93 & 1.86 & .143 & -.028 & -.112 & .136 & .089 & & & & & \\
\hline $\begin{array}{c}\text { Conscientiousness } \\
\text { C }\end{array}$ & 10.90 & 2.23 & .051 & -.025 & -.112 & .159 & .049 & .172 & & & & \\
\hline Religiousness Relig & $3.05^{\mathrm{b}}$ & 1.51 & .063 & -.080 & .013 & .005 & -.057 & .040 & .085 & & & \\
\hline Politics Pol & $4.01^{\mathrm{c}}$ & 1.42 & .020 & -.001 & -.036 & .007 & .124 & .015 & -.063 & -.395 & & \\
\hline Overall I.Q. & 112.53 & 12.69 & -.289 & .027 & -.134 & .135 & .168 & .008 & .075 & -.004 & .016 & \\
\hline $\begin{array}{c}\text { Overall Physical } \\
\text { Attractiveness }\end{array}$ & 107.85 & 13.74 & -.098 & -.147 & -.112 & .185 & .034 & -.012 & .066 & .098 & -.067 & 7.389 \\
\hline
\end{tabular}


Table 3. The regression results for intelligence and attractiveness.

\begin{tabular}{|c|c|c|c|c|c|c|}
\hline & \multicolumn{2}{|c|}{$\begin{array}{c}\text { Overall } \\
\text { Intelligence }\end{array}$} & \multicolumn{2}{|c|}{$\begin{array}{l}\text { Overall Physical } \\
\text { Attractiveness }\end{array}$} & \multicolumn{2}{|c|}{ Facial Attractiveness } \\
\hline & Beta & $\mathrm{t}$ & Beta & $\mathrm{t}$ & Beta & $\mathrm{t}$ \\
\hline Gender & -.297 & -11.81 & -.105 & -4.29 & -.064 & -2.54 \\
\hline BMI & -.030 & -1.22 & -.154 & -6.54 & -.093 & -2.83 \\
\hline Neuroticism & -.076 & -3.30 & -.053 & -2.22 & -.050 & -1.99 \\
\hline Extraversion & .104 & 4.12 & .168 & 6.98 & .131 & 5.29 \\
\hline Openness & .071 & 2.86 & -.028 & -1.19 & -.019 & -0.77 \\
\hline Agreeableness & -.132 & -5.38 & -.157 & -6.50 & -.102 & -4.10 \\
\hline Conscientiousness & .155 & 6.37 & .146 & 6.20 & .121 & 4.98 \\
\hline Religious & -.006 & -0.22 & .048 & 1.89 & .055 & 2.09 \\
\hline Politics & .017 & 0.63 & -.032 & -1.23 & .003 & .12 \\
\hline F statistic & \multicolumn{2}{|c|}{$F(9,1439) ; \mathrm{p}<.001$} & \multicolumn{2}{|c|}{$\mathrm{F}(9,1640) ; \mathrm{p}<.001$} & \multicolumn{2}{|c|}{$\mathrm{F}(9,1641) ; \mathrm{p}<.001$} \\
\hline $\operatorname{Adj} R^{2}$ & \multicolumn{2}{|c|}{.17} & \multicolumn{2}{|c|}{.12} & \multicolumn{2}{|c|}{.06} \\
\hline
\end{tabular}

Five variables strongly predicted self-assessed overall attractiveness. Conscientious, Disagreeable, Extraverted males with lower BMI's gave themselves higher scores. Interestingly, the predictors of Facial Attractiveness were very similar to overall attractiveness but beta's were around half the size and the accounted for around half the variance. The beta's for the regression onto self-rated Facial Attractiveness were similar, but smaller than, those in the regression for overall attractiveness. Interestingly personality traits (Extraversion, Agreeableness and Conscientiousness) were more powerful predictors than gender and shape as measured by BMI.

Table 4 shows regressions for all 10 Gardener "multiple intelligences". Four of the 10 regressions accounted for over $10 \%$ of the variance (Spatial, Logical, Spiritual and Intrapersonal) while four accounted for less than 3\% of the variance (Interpersonal, Musical, Existential and Kinaesthetic). Most of the beta- weights were similar, though not all reached significance. Thus females rated their intelligence significantly lower than males on seven of the intelligences, Neurotics gave lower scores on half, and Conscientiousness participants gave higher scores than less conscientious participants. Some variables seemed little related to self-ratings of multiple intelligences: BMI and political beliefs. Other variables showed a very specific pattern. Thus religious beliefs were related particularly to two self-ratings: Intrapersonal and Spiritual intelligence and Agreeableness related to Logical and Naturalistic intelligence.

Table 5 shows the regressions onto the three Sternberg multiple intelligences. Neither gender, BMI nor political beliefs were related to self-rated emotional intelligence. The most powerful predictors suggested that religious, Conscientious, Stable, Open people believed they had high emotional intelligence.

Finally three regressions were run. Both had gender, BMI, ideology and 


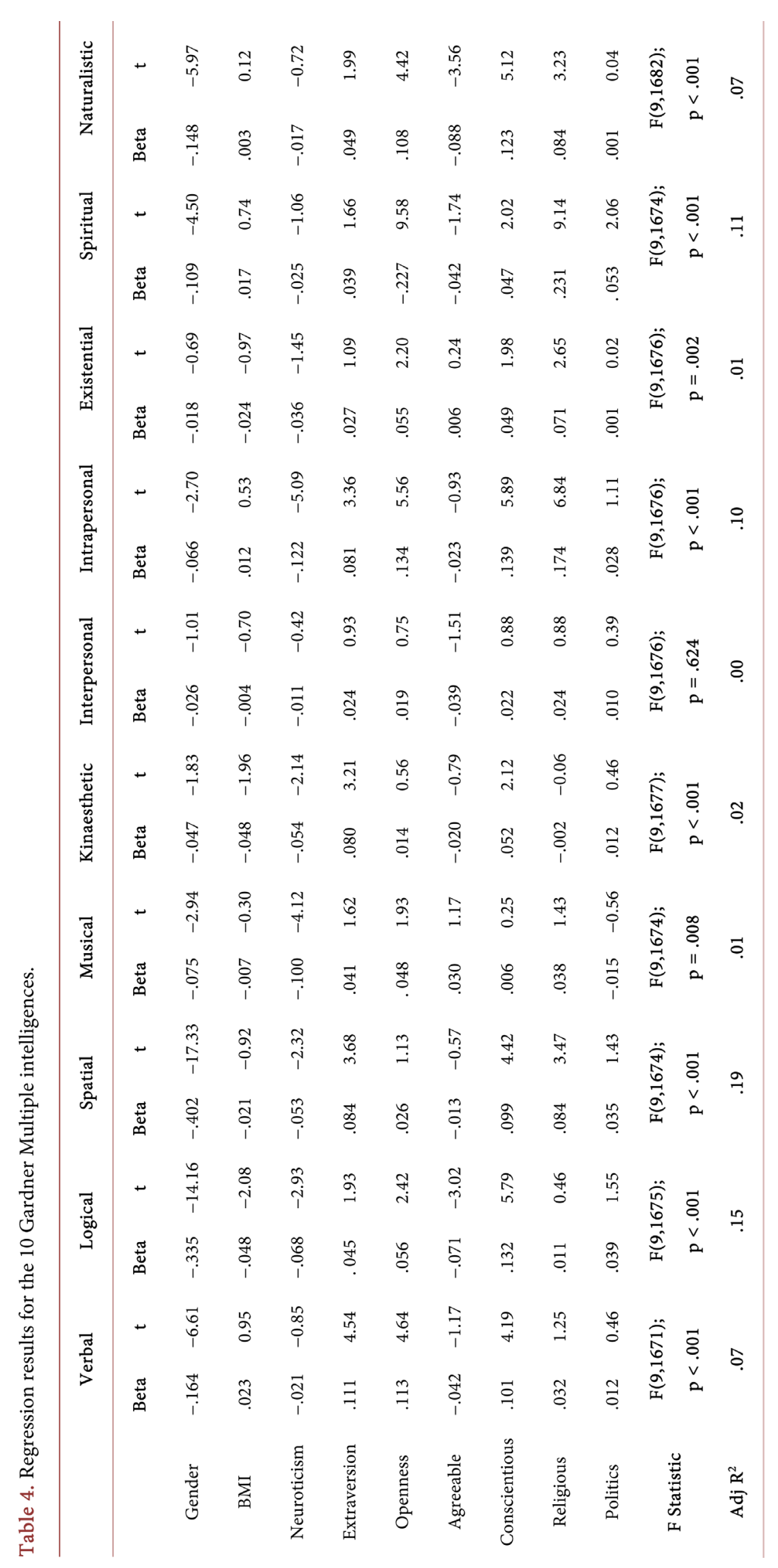


Table 5. Regression results for the three Sternberg Multiple Intelligences.

\begin{tabular}{|c|c|c|c|c|c|c|}
\hline & \multicolumn{2}{|c|}{ Emotional } & \multicolumn{2}{|c|}{ Creative } & \multicolumn{2}{|c|}{ Practical } \\
\hline & Beta & $\mathrm{t}$ & Beta & $\mathrm{t}$ & Beta & $\mathrm{t}$ \\
\hline Gender & -.021 & -0.87 & -.095 & -3.75 & -.103 & -4.03 \\
\hline BMI & .024 & 1.03 & .006 & 0.23 & -.003 & -.106 \\
\hline Neuroticism & -.121 & -5.02 & -.040 & -1.61 & -.032 & -1.30 \\
\hline Extraversion & .090 & 3.72 & .079 & 3.19 & .029 & 1.15 \\
\hline Openness & .109 & 4.52 & .111 & 4.48 & .065 & 2.61 \\
\hline Agreeableness & .027 & 1.12 & -.050 & -1.99 & .007 & 0.29 \\
\hline Conscientiousness & .135 & 5.69 & .077 & 3.18 & .059 & 2.41 \\
\hline Religious & .166 & 6.47 & .015 & 0.56 & .075 & -2.84 \\
\hline Politics & .034 & 1.33 & -.008 & -0.31 & .020 & .75 \\
\hline F Statistic & \multicolumn{2}{|c|}{$\mathrm{F}(9,1676) ; \mathrm{p}<.001$} & \multicolumn{2}{|c|}{$\mathrm{F}(9,1676) ; \mathrm{p}<.001$} & \multicolumn{2}{|c|}{$\mathrm{F}(9,1674) ; \mathrm{p}<.00$} \\
\hline Adj $R^{2}$ & \multicolumn{2}{|c|}{.09} & \multicolumn{2}{|c|}{.04} & \multicolumn{2}{|c|}{.02} \\
\hline
\end{tabular}

personality as predictor variables, but for one self-rated overall intelligence was added when the criterion variable was self-rated attractiveness and in the other self-rated attractiveness was added when the criterion variables was self-rated overall intelligence. Where the criterion was attractiveness, the regression was significant $\left(\mathrm{F}(10,294)=8.86, \mathrm{p}<.001\right.$, Adj $\left.\mathrm{R}^{2}=.21\right)$ with two strong predictor variables: overall self-rated intelligence (Beta $=.24, \mathrm{t}=3.65, \mathrm{p}<.001$ ) and BMI (Beta $=-.19, \mathrm{t}=3.53, \mathrm{p}<.001)$. When the criterion was intelligence the regression was significant $\left(\mathrm{F}(10,294)=20.21\right.$, Adj $\left.\mathrm{R}^{2}=.39\right)$ and the two strongest predictors were gender (Beta $=-.46, \mathrm{t}=9.24$ ) and self-rated attractiveness (Beta $=.18, \mathrm{t}=3.66, \mathrm{p}<.001)$. Thus while gender is particularly important in the selfratings of intelligence and $\mathrm{BMI}$ in the self-ratings of attractiveness, when the self-ratings of the one are included the analysis of the other they are shown to be very important. Indeed the self-ratings correlated at $r=.39$.

Finally an intelligence minus attractiveness score was computed. Thus a high positive score indicated that people believed they were more intelligent than they were attractive, a low score that they were equal on these two factors and a high negative score that they were more attractive than intelligent. There was a strong sex difference on this score (Males: Mean $=7.79, \mathrm{SD}=14.14$; Females: Mean = 2.63, $\mathrm{SD}=12.91 ; \mathrm{F}(1,1630)=49.85, \mathrm{p}<.01)$. This difference score was correlated with Openness $(\mathrm{r}=.18)$, Political Beliefs $(\mathrm{r}=.06)$ and BMI $(\mathrm{r}=.17)$ indicating that left-wing more Open and "heavier" people (with a high BMI) tended to believe they were more intelligent than attractive. The last regression was similar to those above with gender, BMI, ideology and personality as the predictor variables. It was significant $\left(\mathrm{F}(9,304)=3.75, \mathrm{p}<.001\right.$, Adj $\left.\mathrm{R}^{2}=.08\right)$. Three predictor variables were significant: gender (Beta $=-.19, \mathrm{t}=3.28, \mathrm{p}<001)$, BMI (Beta $=.16, \mathrm{t}=2.76, \mathrm{p}<.01)$ and Openness (Beta $=.16, \mathrm{t}=2.76, \mathrm{p}<.01)$. Thus Open males with a low BMI had a bigger difference score. 


\section{Discussion}

This paper replicated and extended various studies in the area. Most, but not all the hypotheses were confirmed. First, the results from nearly all analyses showed that while gender was among the most powerful correlates of overall intelligence, the "academic" intelligences were less powerfully associated with self-rated attractiveness and the "arts" and "social intelligences" which some have suggested are not "real" intelligences (Furnham, 2001). There were medium to large sex differences on self-assessed overall, verbal, spatial and logical intelligence. Indeed on every rating, males provided higher estimates than females, though the differences were not always significant.

Second, in all the self-ratings (overall and multiple intelligence and attractiveness) the relationship with Big Five was consistent. Neurotic and Agreeable people have lower self-estimated scores while Extraverted, Open and Conscientious people gave higher self-estimated scores. This pattern would seem to indicate the profile of a more and less "self-confident" personality profile. It suggests that ability and attractiveness are components of a higher-order general factor of self-esteem. Indeed some measures of self-esteem have different factors which are shown to be inter-correlated (Marsh, Parker, \& Barnes, 1984).

Third, that the "ideological" variables (religious and political beliefs) are little related to the self-ratings, except for the more predictable scales like "spiritual intelligence". Fourth, that BMI was quite unrelated to measures of self-rated intelligence though it was to self-rated attractiveness. The results showed that people with a lower BMI rated themselves as higher on overall physical attractiveness but it did not influence ratings of facial attractiveness. This result no doubt reflects the "slim ideal body shape" that most people in western cultures aspire to.

The results of the final regressions were particularly interesting. They showed that self-ratings of intelligence were related to self-ratings of attractiveness. Both correlational and regression results showed that the two were related. There may be a number of possible explanations for this. The first is that this evidence of rating style is associated with general confidence/self-esteem or lack thereof in most aspects of the self. The second is the possibility that these are accurate ratings in the sense that more intelligent people tend to be physically attractive. There is a disputed literature on this topic which has suggested that there may be assortative mating between intelligent and attractive people and that intelligent males have a better chance of choosing an attractive mate (Judge et al., 2009; Kanazawa, 2011).

It has been established that attractive adults and children are judged to be more intellectually competent, emotionally adjusted and socially appealing. The questions are whether, when or why physical attractiveness reliably and powerfully predicts various social outcome variables. There are two competing theories in this literature: 1) Attractive people are better: their attractiveness is simply a marker of their ability and fitness. 2) Lookism, prejudice and discrimination un- 
fairly (and unscientifically) link physical attractiveness and success at work (Swami \& Furnham, 2008).

There is evidence that physical attractiveness has manifold benefits in everyday life. In 11 meta-analyses Langlois et al. (2000) were able to demonstrate four clear facts. First, there is cross-cultural reliability and agreement about attractiveness. Second, that both attractive children and adults are judged more positively in general compared to less attractive controls even by people who know them. Third, attractive people are treated more positively, and fourth they exhibit more positive behaviours. There are direct effects, though sometimes moderated by gender, age and familiarity. This in part possibly explains why attractive people rate themselves as more intelligent.

One of the consistent criticisms of the self-rating literature is that it often does not contain a valid empirical measure so it might be possible to check the objective against a subjective measure. In this study we did not have an "objective psychometric test" measure of intelligence or attractiveness though the latter seems very difficult to achieve except by using observer ratings. It is also disputed whether indeed there are psychometrically valid measures of the "multiple intelligences" and whether they are "real intelligences" as opposed to traits and skills (Furnham, 2000).

Studies using objective, observer, and self-rated data all show positive correlations between attractiveness and intelligence. This study replicated these findings though it should be pointed out that the correlation was modest $(r=.40)$ and that in regressions around $20 \%$ to $40 \%$ of the variance could be explained. The question for future research is what other individual difference variables might explain more of the variance.

\section{References}

Ackerman, P., \& Wolman, S. (2007). Determinants and Validity of Self-Estimates of Ability and Self-Concept Measures. Journal of Experimental Psychology: Applied, 13, 57-78. https://doi.org/10.1037/1076-898X.13.2.57

Bale, C., \& Archer, J. (2013). Self-Perceived Attractiveness, Romantic Desirability and Self-Esteem. Evolutionary Psychology, 11, 68-84. https://doi.org/10.1177/147470491301100107

Freund, P. H., \& Kasten, N. (2012). How Smart Do You Think You Are? A Meta-Analysis on the Validity of Self-Estimates of Cognitive Ability. Psychological Bulletin, 138, 296-321. https://doi.org/10.1037/a0026556

Furnham, A. (2000). Parents' Estimates of Their Own and Their Children's Multiple Intelligence. British Journal of Developmental Psychology, 18, 583-594. https://doi.org/10.1348/026151000165869

Furnham, A. (2001). Self-Estimates of Intelligence: Culture and Gender Differences in Self and Other Estimates of General (G) and Multiple Intelligences. Personality and Individual Differences, 31, 1381-1405. https://doi.org/10.1016/S0191-8869(00)00232-4

Furnham, A., \& Bunclark, K. (2006) Sex Differences in Parents' Estimations of Their Own and Their Children's Intelligence. Intelligence, 34, 1-14.

https://doi.org/10.1016/j.intell.2005.05.005 
Furnham, A., \& Fukumoto, S. (2008). Japanese Parents' Estimates of Their Own and Their Children's Multiple Intelligence. Japanese Psychological Research, 50, 63-76. https://doi.org/10.1111/j.1468-5884.2008.00362.x

Furnham, A., Tu, B.-L., \& Swami, V. (2012b). Cross-Cultural Differences in Self-Assessed Intelligence: A Comparison of British and Chinese Undergraduates. Psychologia, 55, 21-27. https://doi.org/10.2117/psysoc.2012.21

Gabriel, M., Critelli, J., \& Ee, J. (1994). Narcissistic Illusions in Self-Evaluations of Intelligence and Attractiveness. Journal of Personality, 62, 143-155. https://doi.org/10.1111/j.1467-6494.1994.tb00798.x

Gardner, H. (1999). Intelligence Refrained. New York, NY: Basic Books.

Ivcevic, Z., \& Kaufman, J. (2013). The Can and Cannot Do Attitude: How Self-Estimates of Ability Vary across Ethnic and Socioeconomic Groups. Learning and Individual Differences, 27, 144-148. https://doi.org/10.1016/j.lindif.2013.07.011

Judge, T. A., Hurst, C., \& Simon, L. S. (2009). Does It Pay to Be Smart, Attractive, or Confident (or All Three)? Relationships among General Mental Ability, Physical Attractiveness, Core Self-Evaluations, and Income. Journal of Applied Psychology, 94, 742-755. https://doi.org/10.1037/a0015497

Kanazawa, S. (2011). Intelligence and Physical Attractiveness. Intelligence, 39, 7-14. https://doi.org/10.1016/j.intell.2010.11.003

Kaufman, J. (2012). Self Estimates of General, Crystallized, and Fluid Intelligence in an Ethnically Diverse Population. Learning and Individual Differences, 22, 118-122. https://doi.org/10.1016/j.lindif.2011.10.001

Langlois, J., Kalakais, L., Rubenstein, A., Larson, A., Hallam, M., \& Smoot, M. (2000). Maxims or Myths of Beauty? A Meta-Analytic and Theoretical Review. Psychological Bulletin, 126, 390-423. https://doi.org/10.1037/0033-2909.126.3.390

Marsh, H., Parker, J., \& Barnes, J. (1984). Multidimensional Self-Concepts. American Education Research Journal, 22, 422-444. https://doi.org/10.3102/00028312022003422

McManus, I. C. \& Furnham, A. (2006). Aesthetic Activities and Aesthetic Attitudes. British Journal of Psychology, 97, 555-587. https://doi.org/10.1348/000712606X101088

Moore, F., Filippou, D., \& Perrett, D. (2011). Intelligence and Attractiveness in the Face. Journal of Evolutionary Psychology, 11, 205-217. https://doi.org/10.1556/JEP.9.2011.3.2

Moutafi, J., Furnham, A., \& Paltiel, L. (2004). Why Is Conscientiousness Negatively Correlated with Intelligence? Personality and Individual Differences, 37, 1013-1022.

Paulhus, D., Lysy, D., \& Yik, M. (1998). Self-Report Measures on Intelligence: Are They Useful as Proxy IQ Tests. Journal of Personality, 66, 525-554.

https://doi.org/10.1111/1467-6494.00023

Perez, L., Gonzalez, C., \& Beltran, J. (2010). Parental Estimates of Their Own and Their Relatives' Intelligence. Learning and Individual Differences, 20, 669-676. https://doi.org/10.1016/j.lindif.2010.09.005

Proyer, R. (2011). Being Playful and Smart? The Relations of Adult Playfulness with Psychometric and Self-Estimated Intelligence and Academic Performance. Learning and Individual Differences, 21, 463-467. https://doi.org/10.1016/j.lindif.2011.02.003

Schlosser, T., Dunning, D., Johnson, K., \& Kruger, J. (2013). How Aware Are the Unskilled? Journal of Economic Psychology, 39, 85-100.

Sternberg, R. (1997). Successful Intelligence. New York, NY: Plume.

Stieger, S., Kastner, C. K. Voracek, M., von Stumm, S., Chamorro-Premuzic, T., \& Furnham, A. (2010). Independent Effects of Personality and Sex of Self-Estiumated Intelli- 
gence. Psychological Reports, 107, 553-563.

https://doi.org/10.2466/04.07.09.PR0.107.5.553-563

Storek, J., \& Furnham, A. (2012a). Gender and Gender Role Differences in Domain-Masculine Intelligence and Beliefs about Intelligence: A Study with Mensa UK Members. Personality and Individual Differences, 53, 890-895.

Storek, J., \& Furnham, A. (2012b). Gender and Gender Role Differences in Domain-Masculine Intelligence and Beliefs about Intelligence. Personality and Individual Differences, 53, 890-898.

Swami, V., \& Furnham, A. (2008). The Psychology of Physical Attraction. London: Routledge.

Swami, V., Furnham, A., Georgiages, C., \& Pang, L. (2007) Evaluating Self and Partner Physical Attractiveness. Body Image, 4, 97-101.

https://doi.org/10.1016/j.bodyim.2006.10.003

Swami, V., Waters, L., \& Furnham, A. (2010). Perceptions and Meta-Perceptions of Self and Partner Physical Attractiveness. Personality and Individual Differences, 49, 811-814. https://doi.org/10.1016/j.paid.2010.06.011

Szymanowicz, A., \& Furnham, A. (2011). Gender Differences in Self-Estimates of General, Mathematical, Spatial and Verbal Intelligence: Four Meta-Analyses. Learning and Individual Differences, 21, 493-504.

Von Stumm, S. (2013). Intelligence, Gender, and Assessment Method Affect the Accuracy of Self-Estimated Intelligence. British Journal of Psychology.

https://doi.org/10.1111/bjop.12031

Von Stumm, S., Chamorro-Premuzic, T., \& Furnham, A. (2009). Decomposing Self-Estimates of Intelligence: Structure and Sex Differences across 12 Nations. British Journal of Psychology, 100, 429. https://doi.org/10.1348/000712608X357876 